\title{
Calycosin-loaded nanoliposomes as potential nanoplatforms for treatment of diabetic nephropathy through regulation of mitochondrial respiratory function
}

\author{
Chunrong Huang ${ }^{1 \dagger}$, Lian-Fang Xue ${ }^{2 \dagger}$, Bo Hu${ }^{3}$, Huan-Huan Liu ${ }^{3}$, Si-Bo Huang ${ }^{3}$, Suliman Khan ${ }^{4^{*}}$ and Yu Meng ${ }^{3,5^{*}}$
}

\begin{abstract}
Backgrounds: One of the most common complications in diabetic nephropathy is generation of high levels of ROS which can be regulated by herbal antioxidants. However, polyphenols like calycosin, the bioactive compound of Radix astragali suffer from low solubility and poor bioavailability.

Methods: Therefore, in the present study, calycosin-loaded nanoliposomes were fabricated and characterized by TEM, DLS and FTIR techniques. Afterwards, the drug loading (DL) and entrapment efficiency (EE), drug release, solubility, stability, and pharmacodynamic assays were performed. Finally, the antinephropathic effects of calycosin-loadednanoliposomes on mitochondria of kidney cells were explored by MTT, ROS, MDA, mitochondrial respiratory function assays.

Results: The result showed that the size, hydrodynamic radius, zeta potential, EE, and DL were, $80 \mathrm{~nm}$, $133.99 \pm 21.44 \mathrm{~nm},-20.53 \pm 3.57,88.37 \pm 2.28 \%$, and $7.48 \pm 1.19 \%$, respectively. The outcomes of in vitro release assay showed that calycosin-loaded nanoliposomes were significantly slow-release in dialysis media with pH 1.2, pH6.9 and pH 7.4, at about 30 min, the dissolution of calycosin from nanoliposome became almost complete, and after 2 months, the calycosin-loaded nanoliposomes were still stable. Pharmacokinetic assay revealed that the AUC ${ }_{0-\mathrm{t}}$ of calycosin in calycosin-loaded nanoliposome group was $927.39 \pm 124.91 \mu \mathrm{g} / \mathrm{L}^{*} \mathrm{~h}$, which was 2.26 times than that of the free calycosin group ( $\left.{ }^{* *} P<0.01\right)$. Additionally, the $\mathrm{MRT}_{0-\mathrm{t}}$ and $\mathrm{t}_{1 / 2}$ of calycosin in the calycosin-loaded nanoliposome group were prolonged by 1.54 times and 1.33 times than that of free calycosin group, respectively $\left({ }^{*} P<0.05\right)$. Finally, it was shown that calycosin-loaded nanoliposomes regulated the viability, ROS production, lipid peroxidation and function of mitochondria in kidney cells of diabetic rats as a model of diabetic nephropathy.
\end{abstract}

Conclusion: In conclusion it may be suggested that new therapies based on nano-formulated calycosin can restore mitochondrial function which can improve diabetic nephropathy.

Keywords: Diabetic nephropathy, ROS, Calycosin, Nanoliposome, Mitochondria

\footnotetext{
*Correspondence: suliman.khan18@mails.ucas.ac.cn; yumengmolly@outlook. com

${ }^{\dagger}$ Chunrong Huang and Lian-Fang Xue contributed equally to this study ${ }^{3}$ Department of Nephrology, The First Hospital Affiliated To Jinan University, NO.613, Huangpu Avenue West, Guangzhou 510150, China ${ }^{4}$ Department of Cerebrovascular Diseases, The Second Affiliated Hospital of Zhengzhou University, Zhengzhou, China

Full list of author information is available at the end of the article
}

\section{Introduction}

Diabetes is the most common metabolic disease due to a relative decrease in insulin secretion or function $[1,2]$. Type 2 diabetes is the largest epidemic of the century and is currently the fastest growing disease among other disorders worldwide [3]. Complications of diabetes result

c) The Author(s) 2021. This article is licensed under a Creative Commons Attribution 4.0 International License, which permits use, sharing, adaptation, distribution and reproduction in any medium or format, as long as you give appropriate credit to the original author(s) and the source, provide a link to the Creative Commons licence, and indicate if changes were made. The images or other third party material in this article are included in the article's Creative Commons licence, unless indicated otherwise in a credit line to the material. If material is not included in the article's Creative Commons licence and your intended use is not permitted by statutory regulation or exceeds the permitted use, you will need to obtain permission directly from the copyright holder. To view a copy of this licence, visit http://creativeco mmons.org/licenses/by/4.0/. The Creative Commons Public Domain Dedication waiver (http://creativecommons.org/publicdomain/ zero/1.0/) applies to the data made available in this article, unless otherwise stated in a credit line to the data. 
in two groups of short-term disorders such as hyperglycemia, hyperuricemia, overeating and the appearance of glucose in the urine and long-term or chronic disorders including cardiac, renal, neurological, ocular and ocular injuries [4].

One of the most common microvascular complications in diabetes mellitus is nephropathy, which has been experienced by more than one patient with diabetes mellitus [5]. The kidneys play an important role in the filtration of blood waste products and are more vulnerable than other tissues in high blood sugar conditions [6]. On the other hand, diabetes mellitus is associated with oxidative stress, which is caused by an increase in free oxygen radicals, hydroxyl, or a decrease in the antioxidant defense system $[7,8]$. Oxidative stress caused by high blood sugar in diabetes is also involved in the progression of diabetes complications, including nephropathy [8].

Hyperglycemia in diabetic patients leads to the production of more reactive oxygen species (ROS) in the body [9]. Oxidative stress and cell death that ultimately led to tissue damage in the kidney [9]. Mitochondria are the main source of ROS production in cells and ROS production through the mitochondrial respiratory chain is the main cause of hyperglycemia damage [10].

Today, with two strategies to control blood sugar and reduce oxidative stress in renal mitochondria, it is possible to reduce diabetic nephropathy due to oxidative stress. Treatment of hyperglycemia with chemical drugs or insulin causes several side effects such as chronic anorexia, cerebral atrophy and insulin-induced fatty liver [11]. Therefore, one of the most effective and economical ways to better control the effects of hyperglycemia is to neutralize the high levels of ROS produced and to use herbal antioxidants that are safe and tolerable. For example, it has been indicated that luteolin can show antidiabetic nephropathy in streptozotocin-stimulated diabetic rats [12], or mangiferin mitigates diabetic nephropathy by regulating oxidative stress-mediated signaling pathways [13]. Also, it has been indicated that ursolic acid provides antidiabetic nephropathy through downregulation of oxidative stress and expression of inflammatory mediators in vivo [14]. Some other bioactive compounds such as diosmin [15], ginger [16], and resveratrol [17] have also shown to inhibit the induction of diabetic nephropathy via regulation of oxidative stress and mitochondrial dysfunction.

One of the suggested treatments for the modulation of oxidative stress and mitochondrial function in diabetic nephropathy is the use of calycosin as a potent antioxidant [18].

Dry root extract of Radix astragali is extensively utilized for the mitigation of hypertension [19], inflammation [20], diabetes [21], and cancer [22]. The composition of its dry root extract contains several active metabolites, such as calycosin, saponins and several isoflavonoids [23]. Among these, calycosin provides the main activity of the dry root extract and is known as the typical bioactive compound of Radix astragali [23].

However, as calycosin as a polyphenol shows low solubility property which results in poor absorption and bioavailability and insufficient permeation, makes it difficult to be used as a potential candidate in the development of active drugs [24]. Therefore, some nano-based carriers can be designed to enhance solubility, bioavailability, efficacy, and drug delivery of drugs/compounds [25-28].

Nanoliposomes are colloidal structures consisting of a bilayer membrane [29]. In aqueous solutions, the hydrophobic groups of phospholipids orient inward and their hydrophilic groups orient outward [29]. Today, these nanostructures are used as carriers of drugs, genes, as well as water-insoluble compounds both in vitro and in vivo $[30,31]$. The ability of these nanostructures to encapsulate large amounts of drugs, minimizing unwanted side effects, high efficacy and low toxicity has attracted the interest of researchers. Researchers have studied the delivery of different drugs by these nanocarriers [31]. The results have shown that by using nanoliposomes, drug delivery to target cells and the effectiveness of drugs are improved [30,31]. For example, it has been indicated that the solubility and stability and potency of some plant-based compounds such as curcumin [32], fisetin [33], and resveratrol [34] can be improved after loading of these compounds into the nanoliposomes. In this paper, in addition to fabrication of calycosin-loaded nanoliposomes and their characterization, the protective effects against high glucose (HG)induced oxidative stress in human kidney cells as a model of diabetic nephropathy were investigated.

\section{Materials and methods Materials}

Calycoin, soybean phosphatidylcholine (SPC), cholesterol, 1,2-distearoyl-sn-glycero-3-phosphoethanolamine-N[amino(polyethylene glycol)-2000] (DSPE-mPEG2000), 3-(4,5-dimethylthiazol-2-yl)-2,5-diphenyl-2H-tetrazolium bromide (MTT), and fetal bovine serum (FBS) were purchased from Sigma Co., Ltd. (Miami, USA). All other materials were of analytical grade.

\section{Preparation of calycosin-loaded nanoliposomes}

Calycosin-loaded nanoliposomes were prepared through thin film evaporation-sonication method as described previously [35, 36]: SPC, cholesterol, DSPE-mPEG2000, and calycosin were dissolved with $12 \mathrm{~mL}$ methanol. The molar ratio of SPC to cholesterol and the mass ratio of the calycosin to the total lipid (SPC and cholesterol) (w/w) at the 
condition of $5 \%$ content of DSPE-mPEG2000 were 50:38, $1: 10$, respectively.

The mixture was then dried (vacuum and $55^{\circ} \mathrm{C}$ ) to form a thin film in the rotary evaporation apparatus. Afterward, the samples were hydrated with $20 \mathrm{~mL}$ double distilled water, sonicated $(70 \mathrm{w})$ for $15 \mathrm{~min}$ in an ice bath, extruded by filtering $(0.45 \mu \mathrm{m}$ and $0.22 \mu \mathrm{m})$, and finally freeze-dried at $-20^{\circ} \mathrm{C}$.

\section{Characterization of calycosin-loaded nanoliposomes}

Scanning electron microscope (SEM, TESCAN vega3, Czech Republic) and transmission electron microscopy (TEM, FEI TECHNI, G2-USA) were used to analyze the morphology and size of calycosin-loaded nanoliposomes, respectively. Zeta Sizer (Malvern, UK) was employed to assess the particle size and charge distribution of calycosinloaded nanoliposomes by dissolving them in water solution at room temperature. Fourier transform infrared spectroscopy (FTIR) within $4000-400 \mathrm{~cm}^{-1}$ range was used employing on PerkinElmer Spectrum FT-IR spectrometer (USA).

\section{Entrapment efficiency (EE), drug loading (DL), and in vitro drug release of calycosin-loaded nanoliposomes}

The EE and DL of the prepared calycosin-loaded nanoliposomes were determined by the dialysis method described previously $[35,37]$. Briefly, $700 \mu \mathrm{L}$ of the prepared calycosin-loaded nanoliposomes solution was added into a dialysis bag (cutoff of 8000), followed by putting into $20 \mathrm{~mL}$ of dialysis medium (PBS, pH 7.4). The samples were then shacked (10 h), and centrifuged (3000 rpm, $2 \mathrm{~min}$ ) to determine the free calycosin concentration in the supernatant. Also, $500 \mu \mathrm{L}$ of the calycosin-loaded nanoliposomes were added by $1500 \mu \mathrm{L}$ of methanol, vortexed ( $15 \mathrm{in}$ ), sonicated (5 min), centrifuged (3000 rpm, $2 \mathrm{~min}$ ) to calculate the total calycosin concentration $\left(C_{0}\right) .20 \mathrm{~mL}$ of the prepared calycosin-loaded nanoliposomes powder $\left(V_{0}\right)$ was weighted to calculate the solid powder mass $\left(W_{0}\right) .25 \mu \mathrm{l}$ of the sample was injected into a HPLC system containing Phenomenex ODS analytical column $(150 \mathrm{~mm} \times 4.6 \mathrm{~mm}$, $5 \mu \mathrm{m})$ with a guard column $(30 \mathrm{~mm} \times 10 \mathrm{~mm}, 3 \mu \mathrm{m})$ at $40{ }^{\circ} \mathrm{C}$. The mobile phase was a mixture of methanol: double distilled water as follows:0.05 M KH2PO4=40:60:5, $\mathrm{pH}$ 4.0, with a flow rate of $1.0 \mathrm{ml} / \mathrm{min}$ [37].

The percentage of EE and the DL were then determined according to the formula as follows [35, 37]:

$$
\begin{aligned}
& \mathrm{EE}(\%)=\left(\mathrm{C}_{0}-\mathrm{C}_{1}\right) / \mathrm{C}_{0} \times 100, \\
& \mathrm{DL}(\%)=\mathrm{C}_{0} \cdot \mathrm{V}_{0} \cdot \mathrm{EE} / \mathrm{W}_{0} \times 100 .
\end{aligned}
$$

The simulated gastric fluid was $0.1 \mathrm{~mol} / \mathrm{L} \mathrm{HCl}$ (100 mM, pH 1.2) supplemented with $0.5 \%$ Tween-80, the simulated intestinal fluid was PBS buffer ( $25 \mathrm{mM}, \mathrm{pH} 6.9$ ) containing $0.5 \%$ Tween- 80 , and the simulated physiological buffer was PBS (150 mM, pH 7.4) containing 0.5\% Tween-80. The cumulative drug release was then determined using the following equation [35]:

$$
\begin{aligned}
& \text { Cumulative release rate (\%) } \\
& \begin{array}{l}
=\left[\mathrm{V}_{1} \times\left(\mathrm{C}_{1} \cdots+\mathrm{C}_{\mathrm{i} 1}\right)+\mathrm{V}_{2} \times \mathrm{C}_{\mathrm{i}}\right] \\
\quad /\left(\mathrm{V}_{\mathrm{o}} \times \mathrm{C}_{\mathrm{o}}\right) \times 100
\end{array}
\end{aligned}
$$

where, $V_{1}$ is the sampling amount, $V_{2}$ is the volume of the dialysis medium, $C_{1}-C_{i}$ is the concentration of calycosin at each time point, and $V_{0}$ and $C_{0}$ are the volume and concentration of calycosin-loaded nanoliposomes added to the dialysis bag. Stability of calycosin-loaded nanoliposomes was explored for about two months at $37^{\circ} \mathrm{C}$ by using particle size and encapsulation efficiency of the reconstituted nanoliposome.

\section{Dissolution studies}

The dissolution studies were performed based on the previous study [37]. Briefly, the dissolution medium $(\mathrm{pH}$ 7.4, PBS, $900 \mathrm{ml})$ under stirring $(100 \mathrm{rpm})$ was added by calycosin-loaded nanoliposomes which is equivalent to $50 \mathrm{mg}$ of drug and at different time intervals, $15 \mathrm{~mL}$ samples were removed, replaced, filtrated $(0.45 \mathrm{~m})$, and dissolved in mixed solvent (methanol: distilled water $=5.5: 3.5, \mathrm{v} / \mathrm{v}$ ). Finally, $25 \mu \mathrm{l}$ of the sample was injected into a HPLC system. The rest of the setup was similar to the above-mentioned explanations.

\section{Pharmacokinetics of calycosin-loaded nanoliposomes in rats}

Ten male Sprague-Dawley rats were randomly divided into three groups $(n=8)$ as control, treated with calycosin, and treated with calycosin-loaded nanoliposomes (dissolved in 1\% ethanol). The doses of calycoin groups were $30 \mathrm{mg} / \mathrm{kg}$ for oral administration. After the rats were intragastrically administered with free or Nanoformulated calycosin, the $0.5 \mathrm{~mL}$ blood was taken from the fundus venous plexus of each rat at different time intervals. The blood samples were then centrifuged (4000 rpm, $10 \mathrm{~min}$ ), and the plasma was removed and to stored $-80{ }^{\circ} \mathrm{C}$. The content of the drug in the plasma sample was then calculated by the established LC-MS/ MS method based on the previous report [35].

\section{Animal handling}

To adapt to the environment, two weeks before the experiments, the Sprague-Dawley rats (male, 230-250 g) were placed in separate standard cages and light cycles for $12 \mathrm{~h}$ of light and $12 \mathrm{~h}$ of darkness and access to sufficient water and food at $22^{\circ} \mathrm{C}$. 


\section{Diabetes induction method}

Diabetes was induced in mice by injecting streptozotocin purchased from Sigma (USA). Streptozotocin was dissolved in a citrate buffer $(\mathrm{pH} 6.5,0.1 \mathrm{M})$ and injected at a dose of $65 \mathrm{mg} / \mathrm{kg}$ intraperitoneally. Blood glucose was measured before the test and one week after streptozotocin injection, and mice with blood glucose above $200 \mathrm{dl} / \mathrm{mg}$ were considered diabetic. The calycosin or calycosin-loaded nanoliposomes were dissolved in PBS until it was ready to be injected, and the mice received $30 \mathrm{~kg} /$ $\mathrm{mg}$ of calycosin-loaded nanoliposomes for 4 weeks after becoming diabetic. Vitamin E $(100 \mathrm{mg} / \mathrm{kg})$ was also used as a positive control group.

Animal groups and isolation of mitochondria from kidney Animals were randomly divided in 5 groups which each group consisted of 6 male mice. Group 1: control (receiving no medication), group 2: diabetic group receiving streptozotocin at a dose of $65 \mathrm{mg} / \mathrm{kg}$ intraperitoneally, group 3: received streptozotocin at $65 \mathrm{mg} / \mathrm{kg}$ and after confirmation of diabetes, they received calycosin at $60 \mathrm{mg} / \mathrm{kg}$ intraperitoneally in 4 weeks, group 5: received calycosin-loaded nanoliposomes at $60 \mathrm{mg} / \mathrm{kg}$ intraperitoneally in 4 weeks, group 5: The positive control group was diabetic mice that received $100 \mathrm{mg} / \mathrm{kg}$ of vitamin E for 4 weeks. After the treatment period, the animals were anesthetized with ether, then the kidney tissue was removed, washed with mannitol buffer, and homogenized with normal PBS by homogenizer. The homogenized tissue is first centrifuged $(10,000 \mathrm{rpm}, 10 \mathrm{~min})$ and the supernatant was then discarded and the sediment containing mitochondria was dispersed in Tris buffer on ice [38].

\section{Determination of protein concentration}

Protein concentration was measured as standard using bovine serum albumin (BSA). In all experiments, mitochondria with a protein concentration of $1 \mathrm{mg} / \mathrm{ml}$ were used.

\section{MTT assay}

MTT assay was done to assess the mitochondria viability. $100 \mu \mathrm{l}$ of mitochondrial supernatants were mixed by MTT stock solution $\left(5 \mathrm{mg} \mathrm{mL}^{-1}\right.$ ) for $4 \mathrm{~h}$, followed by removing the supernatants, addition of $150 \mu \mathrm{L}$ DMSO for $5 \mathrm{~min}$, and reading the absorbance of the samples at $570 \mathrm{~nm}$ using a microplate reader (BIO-RAD microplate reader-550).

\section{Measurement of intracellular reactive oxygen species (ROS)}

The generation of intracellular ROS was investigated through the dichlorodihydrofluorescein diacetate
(DCFH-DA) assay. Briefly, $20 \mu \mathrm{l}$ of mitochondrial supernatants were incubated with a DCFH-DA probe $(10 \mu \mathrm{M})$ for $30 \mathrm{~min}$. Then, the fluorescence intensity of the samples was read at $\lambda_{\text {ex }} / \lambda_{\text {em }}$ of $485 \mathrm{~nm} / 530 \mathrm{~nm}$ using a spectrofluorometer (CLARIOstar, Offenburg, Germany).

\section{Measurement of lipid peroxidation}

The level of end product of lipid peroxidation (malondialdehyde [MDA] was measured through thiobarbituric acid reactive substances (TBARS) analysis [39]. Briefly, $20 \mu \mathrm{l}$ of mitochondrial supernatants were added by $390 \mu \mathrm{L}$ trichloroacetate (28\%) and were centrifuged (3500 g for $15 \mathrm{~min})$. Afterward, the supernatant was mixed with TBA $(0.2 \%$ in sodium sulfate) on boiling water and incubated for $40 \mathrm{~min}$, followed by the addition of n-butanol. Finally, the absorbance of samples was read at $532 \mathrm{~nm}$ using a microplate reader (BIO-RAD microplate reader-550).

\section{Measurement of oxygen consumption rate (OCR)}

The OCR of cells was quantified employing a Seahorse XFe24 Analyzer (Agilent, MA, USA). Briefly, after treatment, the cells were washed, incubated with XF DMEM and D-glucose, and incubated in a non- $\mathrm{CO}_{2}$ incubator for $30 \mathrm{~min}$ at $37^{\circ} \mathrm{C}$. The sequential additions of oligomycin with a concentration of $1 \mu \mathrm{M}$ (ATP synthase inhibitor), FCCP with a concentration of $2 \mu \mathrm{M}$ (mitochondrial oxidative uncoupler), and rotenone with a concentration of $1 \mu \mathrm{M}$ (mitochondrial electron transport chain complex I inhibitor) was done to assess the ATP production, maximal respiration, and spare respiratory capacity employing Seahorse Wave software (http://www.seahorsebio.com). The membrane potential was also determined using Cellular Membrane Potential Assay Kit (FluorometricRed) (ab176765) based on manufacturer's instructions provided.

\section{Statistical analysis}

Statistical analysis was carried out using Student's $t$-test and one-way analyses of variance (ANOVA). Results were reported as means \pm standard errors (SEs) of three $(n=3)$ independent experiments. $P<0.05$ was considered significant.

\section{Results and discussion}

\section{Characterization of calycosin-loaded nanoliposome}

The size of calycosin-loaded nanoliposomes was characterized by TEM analysis (Fig. 1a). The histogram of size distribution determined by TEM revealed the synthesized drug-loaded nanoliposomes showed a size range of 20-200 nm with average size of around $80 \mathrm{~nm}$ (Fig. 1a, inset, 100 nanoliposomes were counted in the analysis). The SEM image showed that synthesized calycosin-loaded nanoliposomes were spherical NPs with 

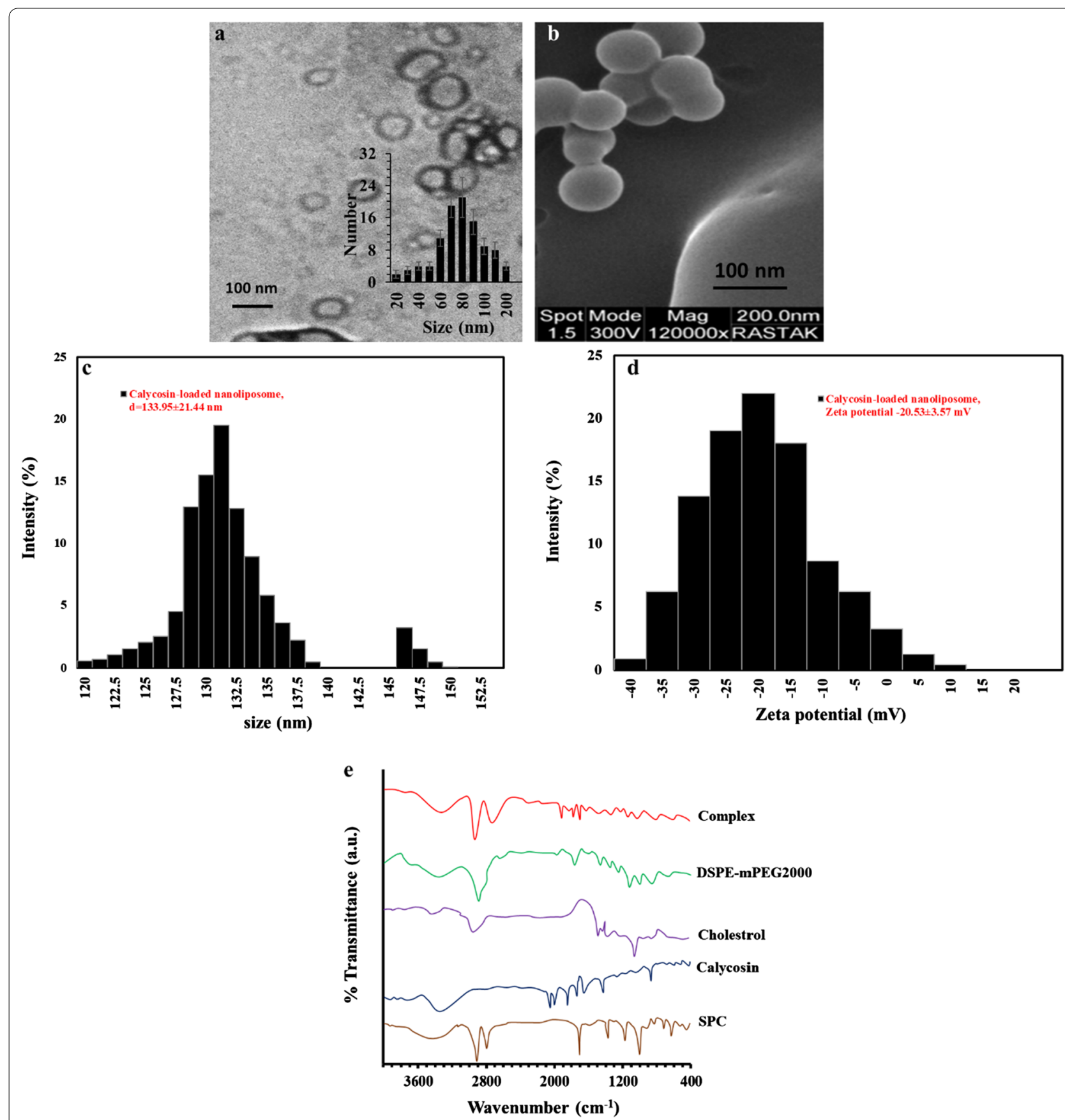

Fig. 1 a TEM (inset: size distribution histogram), b SEM, c DLS histogram, d zeta potential histogram, e FTIR analysis of fabricated calycosin-loaded nanoliposomes. The experiment was done at room temperature

very homogeneous distribution and a size of around $80 \mathrm{~nm}$ (Fig. 1b), which is in good agreement with TEM analysis. DLS is known as one of the most sensitive approaches employed for the determination of the colloidal stability of nano-based materials based on the hydrodynamic radius [40]. The calycosin-loaded nanoliposomes were also characterized by DLS technique and the result showed that the average particle size distribution was in the range of $120-150 \mathrm{~nm}$ with a mean size of $133.99 \pm 21.44 \mathrm{~nm}(\mathrm{PDI}=0.201 \pm 0.068)$ (Fig. 1c). The narrow distribution of histogram also indicates the uniform distribution of calycosin-loaded nanoliposomes.

Zeta potential study was also done to measure the charge distribution of fabricated nanoliposomes. It was 
shown that the mean zeta potential of calycosin-loaded nanoliposomes was $-20.53 \pm 3.57 \mathrm{mV}$ (Fig. 1d), indicating the good colloidal stability of nanoparticles.

Calycosin is a typical polyphenol with poor hydrophilic features. The partial interaction of the calycosin with the polar part of the phospholipid can result in increasing their dissolution rate. It has been indicated that calycosin can interact with liposome membranes [41]. According to the TEM and SEM images, the structure of drug-loaded nanoliposome was obvious, and the loading of calycosin did not destabilize the typical structure of lipids.

The formation of the of calycosin-loaded nanoliposomes complex was assessed by FTIR spectroscopy by comparing the vibration band of the complex with the individual compounds. As shown in Fig. 1e, there were some differences in different regions between the complex and each of its individual compounds. The spectrum of complex revealed a new peak at $1331 \mathrm{~cm}^{-1}$, which was not appeared in other components. This spectrum also demonstrated a reduced intensity in the peak at $1697 \mathrm{~cm}^{-1}$. These data indicated that hydrogen-bonding between calycosin and SPC may play an important role during the final complex as calycosin-loaded nanoliposomes. These differences were determined at $\mathrm{N}-\mathrm{O}$ band vibration regions $\left(1400-1300 \mathrm{~cm}^{-1}\right)$ and $\mathrm{P}-\mathrm{O}$ band vibration regions $\left(1700-1800 \mathrm{~cm}^{-1}\right)$. Therefore, it can be indicated that hydrogen-bonding forms between polar region of calycosin and cholin group of SPC.

\section{Drug loading and in vitro drug release}

Based on the experimental set up mentioned in the method section, the EE was $88.37 \pm 2.28 \%$, and the DL was $7.48 \pm 1.19 \%$. The outcomes of in vitro release experiments were displayed in Fig. 2. In the simulated gastric medium, the cumulative release (\%) of calycosin was about $32 \%$ at $1 \mathrm{~h}$ and almost complete release (\%) at $20 \mathrm{~h}$; calycosin-loaded nanoliposomes released $11 \%$ at $1 \mathrm{~h}, 44 \%$ at $20 \mathrm{~h}$, and $100 \%$ at $80 \mathrm{~h}$. In the simulated intestinal fluid, the cumulative release (\%) of calycosin was about $32 \%$ at $1 \mathrm{~h}, 90 \%$ at $20 \mathrm{~h}$, and almost complete release at $100 \mathrm{~h}$; calycosin-loaded nanoliposome released $6 \%$ at $1 \mathrm{~h}, 44 \%$ at $20 \mathrm{~h}$, and $100 \%$ at $120 \mathrm{~h}$. In the simulated physiological fluid, the cumulative release (\%) of calycosin was about $7 \%$ at $1 \mathrm{~h}, 55 \%$ at $20 \mathrm{~h}$, and almost complete release at $120 \mathrm{~h}$; calycosin-loaded nanoliposome released $2 \%$ at $1 \mathrm{~h}$, $15 \%$ at $20 \mathrm{~h}$, and $100 \%$ at $>120 \mathrm{~h}$.

The outcomes of in vitro release assays indicated that calycosin-loaded nanoliposomes were remarkably slowrelease in dialysis media with $\mathrm{pH} 1.2, \mathrm{pH} 6.9$ and $\mathrm{pH}$ 7.4, and the release rate in buffer solution with $\mathrm{pH} 1.2$ was faster than that in buffer solutions with $\mathrm{pH} 6.9$ and $\mathrm{pH}$ 7.4. This may be due to the reason that nanoliposome are vulnerable in acidic media and provide poor stability.

\section{Dissolution study}

Figure 3 displays the dissolution profile of calycosin from nanoliposome in PBS buffer ( $\mathrm{pH} 7.4$ ). At about $30 \mathrm{~min}$, the dissolution of calycosin from nanoliposome became almost complete. It can be indicated that the nanoliposomes formed an encapsulation medium on contact with the solution and calycosin were entrapped in liposomes. However, for free drug, the dissolution rate of calycosin was low.

\section{Stability of calycosin-loaded nanoliposome}

After 2 months, the appearance of calycosin-loaded nanoliposome still was uniform, and the prepared nanoliposome could form a nanoliposome dispersion upon contact with solution. Table 1 tabulated that particle size (nm) and EE (\%) of calycosin-loaded nanoliposome have no significant change at $37^{\circ} \mathrm{C}$ for 2 months.

\section{In vivo pharmacokinetics}

The pharmacokinetic curves of calycosin after oral administration of a single dose of calycosin and calycosin-loaded nanoliposome were demonstrated in Fig. 4. The outcomes indicated that under a single dose of caly$\operatorname{cosin}(30 \mathrm{mg} / \mathrm{kg})$, the plasma concentration of calycosin in the nanoliposome group was always higher than that in the free calycosin group. Also, the main pharmacokinetic parameters of calycosin in both groups were summarized in Table 2.

The data revealed that under the iso-dose calycosin in both free calycosin- and calycosin-loaded nanoliposometreated groups, the $\mathrm{AUC}_{0-\mathrm{t}}$ of calycosin in calycosinloaded nanoliposome group was $927.39 \pm 124.91 \mu \mathrm{g} / \mathrm{L} * \mathrm{~h}$, which was 2.26 times than that of the free calycosin group $(* * P<0.01)$. Additionally, the $\mathrm{MRT}_{0-\mathrm{t}}$ and $\mathrm{t}_{1 / 2}$ of calycosin in the calycosin-loaded nanoliposome group were prolonged by 1.54 times and 1.33 times than that of the free calycosin group, respectively $\left({ }^{*} P<0.05\right)$. The data revealed that calycosin-loaded nanoliposome could not only mitigate the first-pass influence of calycosin to improve its oral absorption, but also prolong its resident time to provide the slow-release impact.

The pharmacokinetic data showed that calycosinloaded nanoliposome could not only decrease the firstpass impact of calycosin to improve its oral absorption, but also prolong its mean bioavailability to provide the slow-release effect.

\section{MTT assay}

MTT assay was performed to assess the mitochondrial viability of diabetic rats treated with free calycosin or calycosin-loaded nanoliposomes. As shown in Fig. 5, the mitochondrial viability significantly decreased in diabetic rats $\left({ }^{* * * *} P<0.001\right)$ compared to the control group. 

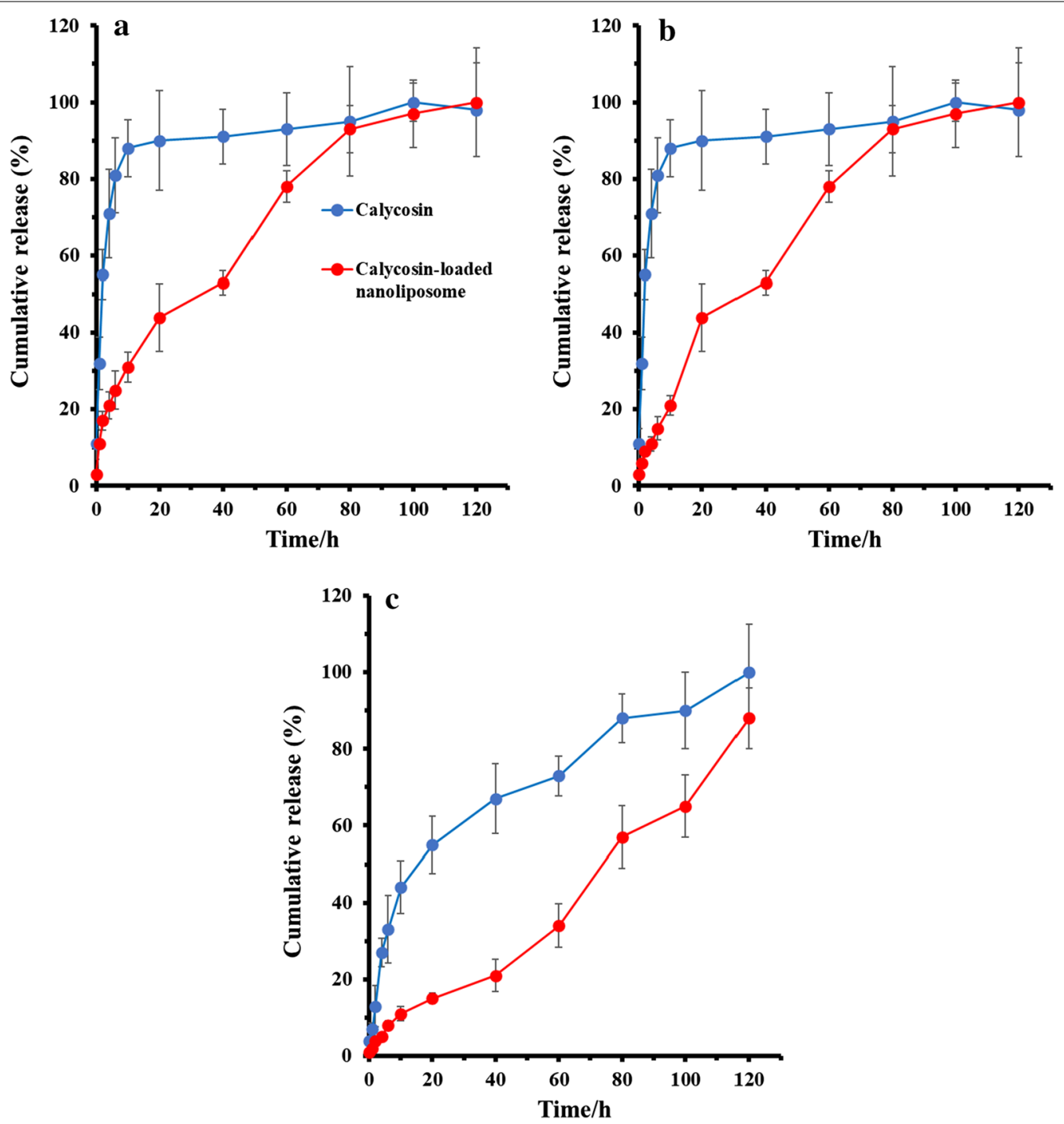

Fig. 2 In vitro release of calycosin-loaded nanoliposome and free calycosin at different release media: a (pH 1.2), b PBS (pH 6.9), c PBS (pH 7.4) (mean $\pm \mathrm{SD}, n=3$ )

However, treatment of the cells with calycosin and calycosin-loaded nanoliposome led to a significant recovery of mitochondrial viability in comparison with diabetic rats. Also, it was determined that the protective impact of calycosin-loaded nanoliposome was more significant $\left({ }^{\$} P<0.05\right)$ than free calycosin and was comparable with vitamin E (Fig. 3b). This outcome displayed that calycosin-loaded nanoliposome can be a potential candidate in the protection of the kidney cells against diabetes.

\section{ROS and MDA assay}

The generation of ROS was assessed in diabetic rats through DCFH-DA assay. As depicted in Fig. 6a, diabetic rats showed a significant $\left({ }^{* * * *} P<0.001\right)$ increase in DCF fluorescence intensity associated with the ROS level. However, treatment with free calycosin and calycosinloaded nanoliposome potentially reduced the generation of ROS, as indicated by the lower DCF fluorescence intensity (Fig. 6a). MDA, which is the end product of lipoperoxidation and as a potential indicator of oxidative stress was assessed to examine the protective effect of calycosin-loaded nanoliposome against oxidative stress in diabetic rats. A significant increase $\left({ }^{* * *} P<0.001\right)$ in the MDA level was detected in diabetic rats relative to the control cells, whereas treatment with calycosin or calycosin-loaded nanoliposome determined a remarkable decrease in lipid peroxidation (Fig. 6b). The results also indicated that the protective effect of calycosin-loaded 


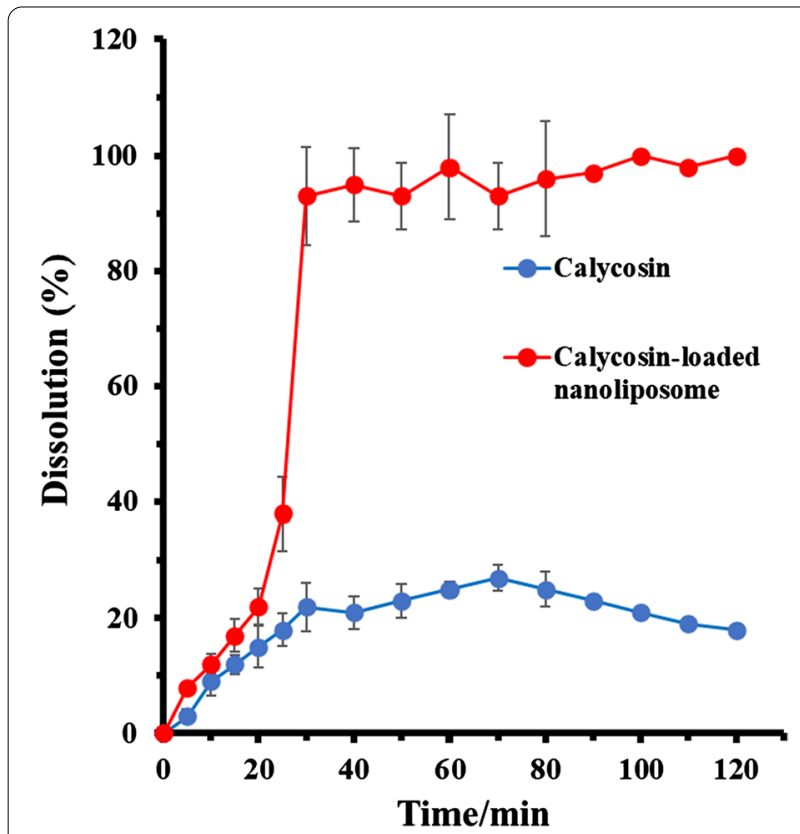

Fig. 3 Dissolution behaviors of calycosin-loaded nanoliposome in PBS buffer ( $\mathrm{pH}$ 7.4) (mean $\pm \mathrm{SD}, n=3)$

Table 1 Stability of calycosin-loaded nanoliposome at the temperature of $37^{\circ} \mathrm{C}$ for 2 months

\begin{tabular}{lll}
\hline $\begin{array}{l}\text { Time (month, } \\
\boldsymbol{n}=\mathbf{3})\end{array}$ & Average size $(\mathrm{nm}, \boldsymbol{n = 3})$ & $\begin{array}{l}\text { Entrapment } \\
\text { efficiency }(\mathbf{n m}, \\
\boldsymbol{n}=\mathbf{3})\end{array}$ \\
\hline 0 & $133.99 \pm 21.44$ & $88.37 \pm 2.28 \%$ \\
1 & $149.07 \pm 18.64$ & $86.19 \pm 1.37$ \\
2 & $163.71 \pm 27.68$ & $85.67 \pm 1.59$ \\
\hline
\end{tabular}

nanoliposome against diabetes-induced generation of $\operatorname{ROS}\left({ }^{\$} P<0.01\right)$ and MDA $\left({ }^{\$} P<0.05\right)$ was more pronounced than free calycosin and was comparable with vitamin E. This data determined that treatment of diabetic rats with calycosin-loaded nanoliposome inhibited the increase in ROS and MDA level, mitigated lipoperoxidation of the cell membrane and decreased cell damage.

\section{Mitochondrial respiration dysfunction}

It has been well-documented that the mitochondrial function is important to improve cell survival [42]. To further assay the protective impact of calycosin-loaded nanoliposome on mitochondrial respiratory function, the OCR amounts and mitochondrial membrane potential of diabetic rats treated with calycosin or calycosinloaded nanoliposome were determined. Indeed, in this assay after the sequential addition of some mitochondrial stressors, OCR values of the mitochondria were analyzed using a Seahorse XFe24 Analyzer (Fig. 7a-f). It

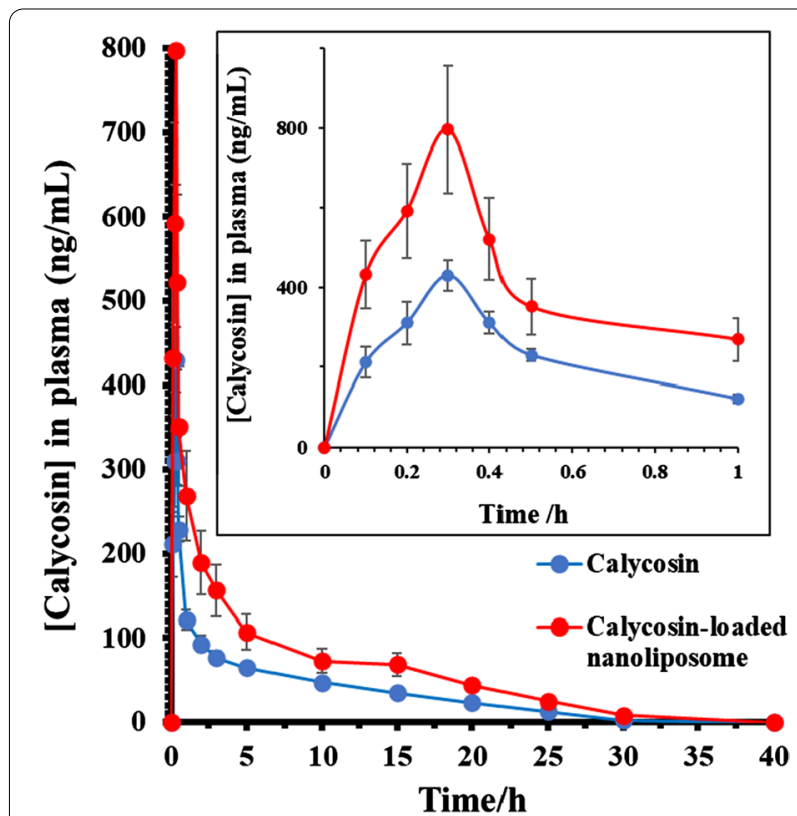

Fig. 4 Pharmacokinetic curves of calycosin-loaded nanoliposome and free calycosin after oral administration of a single dose of calycosin (30 mg/kg) (mean $\pm S D, n=5)$

Table 2 Main pharmacokinetic parameters of free calycosin and calycosin-loaded nanoliposome group after oral administration $($ mean $\pm \mathrm{SD}, n=3$ )

\begin{tabular}{llcl}
\hline Parameters & Unit & Free calycosin group & $\begin{array}{l}\text { Calycosin-loaded } \\
\text { nanoliposome } \\
\text { group }\end{array}$ \\
\hline $\mathrm{AUC}_{0-t}$ & $\mu \mathrm{g} / \mathrm{L}^{*} \mathrm{~h}$ & $409.11 \pm 67.29$ & $927.39 \pm 124.91^{* *}$ \\
$\mathrm{AUC}_{0-\infty}$ & $\mu \mathrm{g} / \mathrm{L}^{*} \mathrm{~h}$ & $421.09 \pm 73.27$ & $945.37 \pm 158.91^{* *}$ \\
$\mathrm{MRT}_{0-t}$ & $\mathrm{~h}$ & $8.68 \pm 1.27$ & $13.39 \pm 1.93^{*}$ \\
$t_{1 / 2}$ & $\mathrm{~h}$ & $6.98 \pm 0.96$ & $9.29 \pm 0.88^{*}$ \\
$T_{\max }$ & $\mathrm{h}$ & $0.19 \pm 0.017$ & $0.14 \pm 0.019^{*}$ \\
$C_{\max }$ & $\mu \mathrm{g} / \mathrm{L}^{*} \mathrm{~h}$ & $298.27 \pm 35.81$ & $331.52 \pm 47.08$
\end{tabular}

${ }^{*} P<0.05,{ }^{*} P<0.01$ vs free calycosin group

AUC Area under the time-concentration curve, $t_{1 / 2}$ Elimination half-life, MRT Mean residence time, $T_{\max }$ The time of peak concentration, $C_{\max }$ Peak concentration

was seen that diabetic rats showed a significant decrease in ATP production (Fig. 7a), spare respiratory capacity (Fig. 7b), maximal respiration (Fig. 7c), coupling efficiency (Fig. 7d), OCR/extracellular acidification rate (ECAR) ratio (Fig. 7e), and membrane potential (Fig. 7f) compared with those in the control group. However, calycosin-loaded nanoliposome determined to reverse these mitochondrial malfunctions with statistical significance relative to the free calycosin. Taken together, these data suggested that calycosin-loaded nanoliposome treatment 


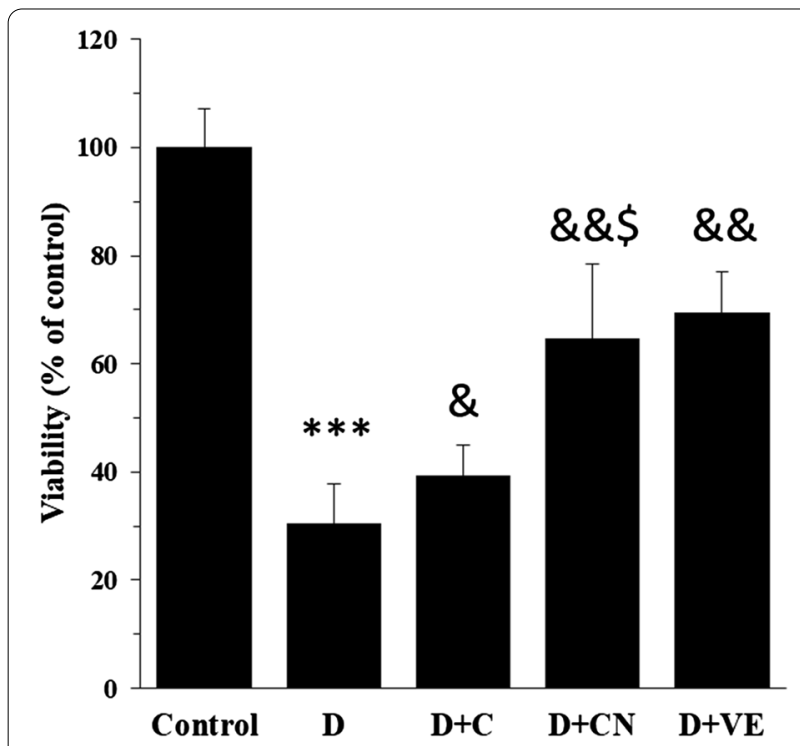

Fig. 5 Protective effect of calycosin-loaded nanoliposome on mitochondria of diabetic rats. Data represent mean $\pm S E M$. of three independent runs. ${ }^{* * *} P<0.001$ relative to control; ${ }^{*} p<0.05$, $\&<0.01$ relative to $D$-treated group; ${ }^{\$} P<0.05$ relative to $D+C$ - treated group. Diabetic group (D), diabetic group treated with calycosin $(D+C)$, diabetic group treated with calycosin-loaded nanoliposome $(D+C N)$, diabetic group treated with vitamin $E(D+V E)$

could protect diabetic rats against oxidative stress-triggered mitochondrial respiration dysfunction.

Lack of strong antioxidant defense can lead to activation of the signaling pathway associated with oxidative stress in diabetic nephropathy $[43,44]$. In fact, one of the most important cellular responses to high glucose concentrations is oxidative stress and increased production of ROS in the mitochondria and ultimately the occurrence of apoptosis in cells and tissues [45]. Physiologically, some endogenous antioxidant molecules such as superoxide dismutase, glutathione peroxidase, catalase, and bilirubin reductase are excreted by oxidative stress-induced renal cell damage [46]. But in people with diabetes the generation of free radical increases due to decrease in the level of antioxidant systems, resulting in a continuous chain reaction of lipid peroxidation mitochondrial dysfunction [46].

Due to the low solubility and poor bioavailability of polyphenols, therapeutic perspectives of bioactive polyphenols through their nanoformulations against diabetic neuropathy have been suggested [47]. Indeed, it has been documented that polyphenol-stabilized nanoparticles can show potential anti-diabetic activity $[24,48,49]$.

The physicochemical stability of calycosin is influenced by different parameters and therefore their metabolism, bioavailability, and pharmacokinetic activities are changed. These drawbacks can be overcome by encapsulation of the calycosin into nano-based platforms. An increase in the bioavailability of calycosin-loaded nanoliposomes was observed with an enhancement in their solubility, sustained drug release, improvement of its pharmacokinetic features, and promotion of its antidiabetic-nephropathy effects. The antidiabetic-nephropathy activity of calycosin was reported to be increased after nanoliposome encapsulation.
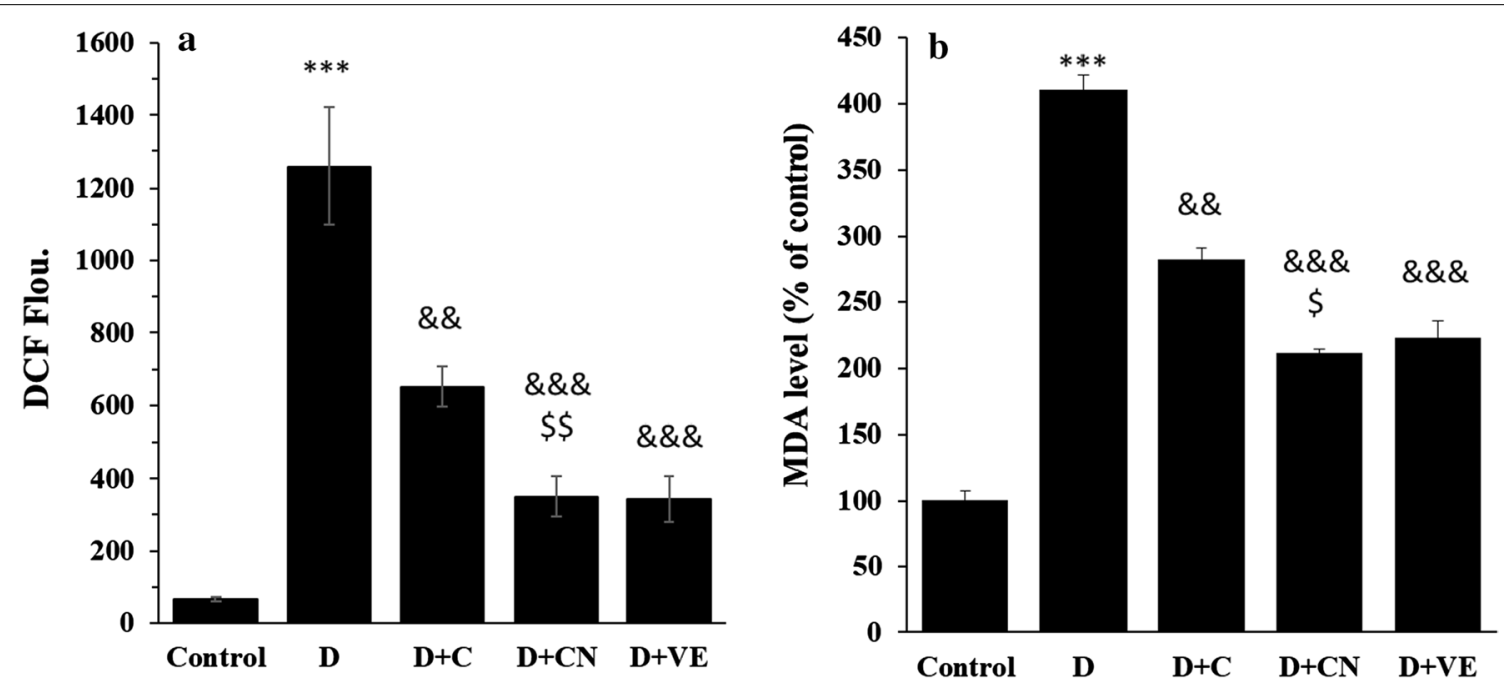

Fig. 6 A ROS, B MDA levels in mitochondria of diabetic rats. Data represent mean \pm SEM. of three independent runs. ${ }^{* * *} P<0.001$ relative to control; $\& \&<0.01$, \&\& $P<0.001$ relative to D-treated group; $\$ \$ P<0.01$ relative to $D+C$ - treated group. Diabetic group (D), diabetic group treated with calycosin $(D+C)$, diabetic group treated with calycosin-loaded nanoliposome $(D+C N)$, diabetic group treated with vitamin $E(D+V E)$ 


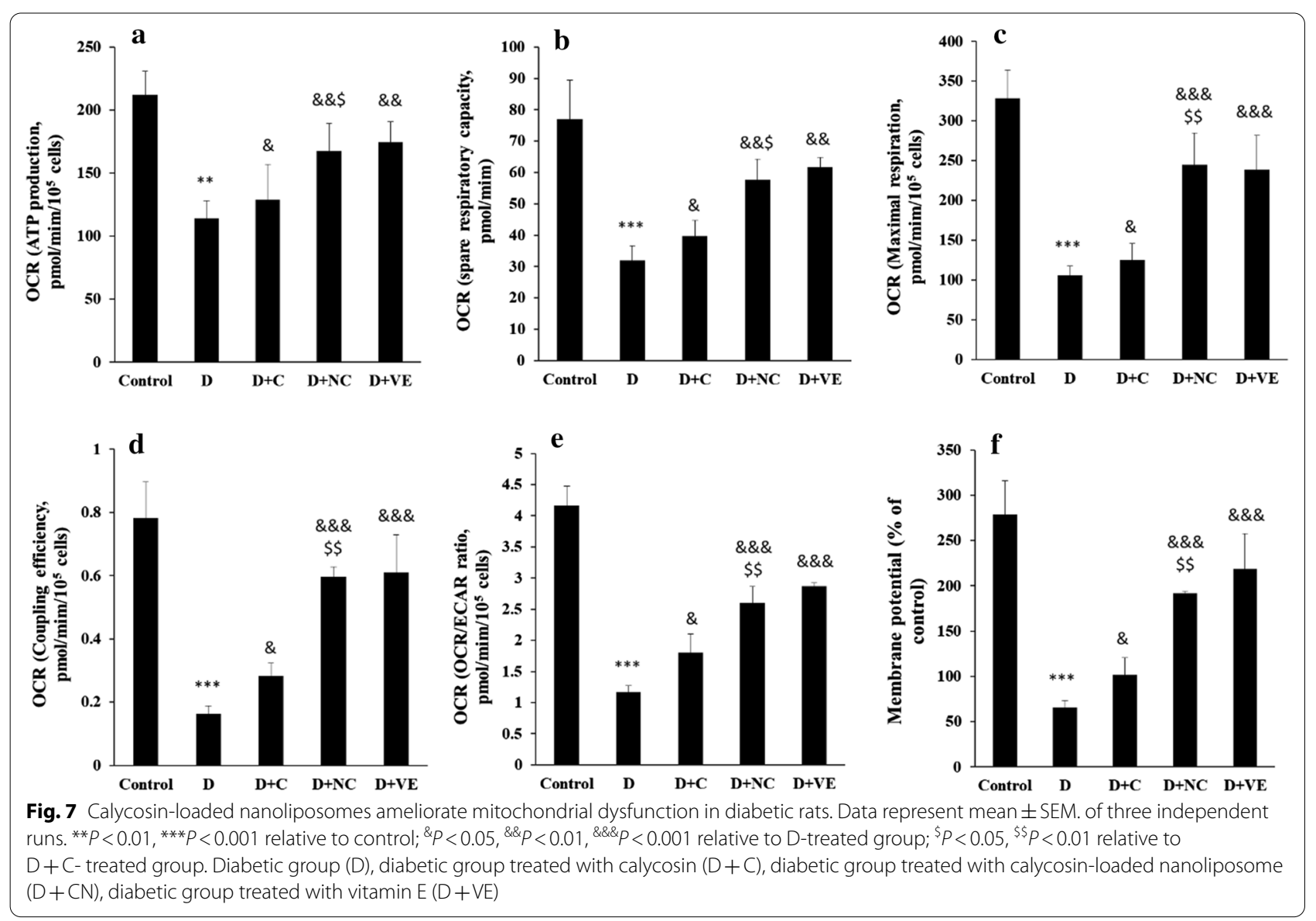

In this study, evidence was provided that mitochondrial function was reduced in the predominant form of diabetic nephropathy in rats which is in good agreement with other reported studies [50-52]. We found that calycosin-loaded nanoliposomes play a key role in recovering mitochondrial function of kidney cells. This means that new therapies based on nano-formulated calycosin can restore mitochondrial function to normal and their content can improve or even stop chronic kidney disease.

\section{Conclusion}

According to the results of the other studies and the data of the present study, it can be boldly claimed that calycosin can play a key role in reducing the damage caused by oxidative stress in kidney cells as an antioxidant. However, further and more extensive studies on the exact mechanism or molecular and cellular mechanisms influencing the pharmacological function of calycosin are necessary for its treatment or control of diabetic nephropathy and other diseases. The results of this study show that calycosin-loaded nanoliposomes can be useful in inhibiting the diabetes mellitus-induced kidney cell damage in which the cells are under oxidative stress due to recovery of mitochondrial function.

\section{Acknowledgements}

Not applicable.

\section{Authors' contributions}

CH, L-FX, BH, H-HL, S-BH: Methodology, Analysis, verification, revision; SK, YM: conceptualization, analysis, validation, supervision; writing. All authors read and approved the final manuscript.

\section{Funding}

This work was supported by the Natural Science Foundation of Guangdong, China 2018A030313527, the Basic and Applied basic research Foundation of Guangdong Province, China 2019A1515010176, Science and technology project of Shenzhen, China JCYJ20190808095615389 and the Research Project of Guangdong Provincial Bureau of Traditional Chinese Medicine, China 20191089. The authors also gratefully acknowledge the China Postdoctoral Science Foundation research grant NO. 2020M672291.

\section{Availability of data and materials}

The datasets used and analyzed during the current study are available from the corresponding author on reasonable request.

\section{Declarations}

Ethics approval and consent to participate

All animal use procedures were carried out in accordance with the Regulations of Experimental Animal Administration issued by the State Committee of 
Science and Technology of the People's Republic of China, with the approval of the Ethics Committee in our university (Ethical Inspection Approval Office with NO.: 2018-048).

\section{Consent for publication}

All authors read and approve the final manuscript.

\section{Competing interests}

The authors declare that they have no competing interests.

\section{Author details}

'Department of Gastroenterology, The First Hospital Affiliated To Jinan University, Guangzhou, China. ${ }^{2}$ Department of Clinical Pharmacy, The First Affiliated Hospital of Jinan University, Guangzhou, China. ${ }^{3}$ Department of Nephrology, The First Hospital Affiliated To Jinan University, NO.613, Huangpu Avenue West, Guangzhou 510150, China. ${ }^{4}$ Department of Cerebrovascular Diseases, The Second Affiliated Hospital of Zhengzhou University, Zhengzhou, China. ${ }^{5}$ Central laboratory, the Fifth Affiliated Hospital of Jinan University, Guangzhou, China.

Received: 21 February 2021 Accepted: 28 May 2021

Published online: 13 June 2021

\section{References}

1. DeFronzo RA, Ferrannini E, Groop L, Henry RR, Herman WH, Holst JJ, Hu FB, Kahn CR, Raz I, Shulman GI, Simonson DC. Type 2 diabetes mellitus. Nat Rev Dis Primers. 2015;1(1):1-22.

2. Broom D, Whittaker A. Controlling diabetes, controlling diabetics: moral language in the management of diabetes type 2. Soc Sci Med. 2004;58(11):2371-82.

3. Jaacks LM, Siegel KR, Gujral UP, Narayan KV. Type 2 diabetes: a 21st century epidemic. Best Pract Res Clin Endocrinol Metab. 2016;30(3):331-43.

4. Nathan DM. Diabetes: advances in diagnosis and treatment. JAMA. 2015;314(10):1052-62.

5. Gross JL, De Azevedo MJ, Silveiro SP, Canani LH, Caramori ML, Zelmanovitz T. Diabetic nephropathy: diagnosis, prevention, and treatment. Diabetes Care. 2005;28(1):164-76.

6. Dronavalli S, Duka I, Bakris GL. The pathogenesis of diabetic nephropathy. Nat Clin Pract Endocrinol Metab. 2008:4(8):444-52.

7. Umanath K, Lewis JB. Update on diabetic nephropathy: core curriculum 2018. Am J Kidney Dis. 2018;71(6):884-95.

8. Sagoo MK, Gnudi L. Diabetic nephropathy: Is there a role for oxidative stress? Free Radical Biol Med. 2018;20(116):50-63.

9. Sifuentes-Franco S, Padilla-Tejeda DE, Carrillo-Ibarra S, Miranda-Díaz AG. Oxidative stress, apoptosis, and mitochondrial function in diabetic nephropathy. Int J Endocrinol. 2018;1:1-10.

10. Sifuentes-Franco S, Pacheco-Moisés FP, Rodríguez-Carrizalez AD, Miranda-Díaz AG. The role of oxidative stress, mitochondrial function, and autophagy in diabetic polyneuropathy. J Diabetes Res. 2017;24(1):1-8.

11. Pérez-Sánchez $\mathrm{H}$, den-Haan H, Peña-García J, Lozano-Sánchez J, Martínez Moreno ME, Sánchez-Pérez A, Muñoz A, Ruiz-Espinosa P, Pereira AS, Katsikoudi A, Gabaldón Hernández JA. DIA-DB: a database and web server for the prediction of diabetes drugs. J Chem Inf Model. 2020;60(9):4124-30.

12. Wang GG, Lu XH, LiW, Zhao X, Zhang C. Protective effects of luteolin on diabetic nephropathy in STZ-induced diabetic rats. Evid Based Complement Alternat Med. 2011;1:2011-9.

13. Pal PB, Sinha K, Sil PC. Mangiferin attenuates diabetic nephropathy by inhibiting oxidative stress mediated signaling cascade, TNFa related and mitochondrial dependent apoptotic pathways in streptozotocin-induced diabetic rats. PLOS ONE. 2014;9(9):e107220-8.

14. Xu HL, Wang XT, Cheng Y, Zhao JG, Zhou YJ, Yang JJ, Qi MY. Ursolic acid improves diabetic nephropathy via suppression of oxidative stress and inflammation in streptozotocin-induced rats. Biomed Pharmacother. 2018;1(105):915-21.

15. Ahmed S, Mundhe N, Borgohain M, Chowdhury L, Kwatra M, Bolshette $\mathrm{N}$, Ahmed A, Lahkar M. Diosmin modulates the NF-kB signal transduction pathways and downregulation of various oxidative stress markers in alloxan-induced diabetic nephropathy. Inflammation. 2016;39(5):1783-97.

16. Al Hroob AM, Abukhalil MH, Alghonmeen RD, Mahmoud AM. Ginger alleviates hyperglycemia-induced oxidative stress, inflammation and apoptosis and protects rats against diabetic nephropathy. Biomed Pharmacother. 2018;1(106):381-9.

17. Chang CC, Chang CY, Wu YT, Huang JP, Yen TH, Hung LM. Resveratrol retards progression of diabetic nephropathy through modulations of oxidative stress, proinflammatory cytokines, and AMP-activated protein kinase. J Biomed Sci. 2011;18(1):1.

18. El-Tantawy WH, Temraz A. Management of diabetes using herbal extracts. Arch Physiol Biochem. 2018;124(5):383-9.

19. Wu JS, Li JM, Lo HY, Hsiang CY, Ho TY. Anti-hypertensive and angiotensinconverting enzyme inhibitory effects of Radix Astragali and its bioactive peptide AM-1. J Ethnopharmacol. 2020;23(254):112724-31.

20. Bai S, He C, Zhang K, Ding X, Zeng Q, Wang J, Peng H, Bai J, Lu H, Xuan Y, Su Z. Effects of dietary inclusion of Radix Bupleuri and Radix Astragali extracts on the performance, intestinal inflammatory cytokines expression, and hepatic antioxidant capacity in broilers exposed to high temperature. Anim Feed Sci Technol. 2020;1 (259):114288-95.

21. Yang F, Qu Q, Zhao C, Liu X, Yang P, Li Z, Han L, Shi X. Paecilomyces cicadae-fermented Radix astragali activates podocyte autophagy by attenuating PI3K/AKT/mTOR pathways to protect against diabetic nephropathy in mice. Biomed Pharmacother. 2020;1 (129):1 10479-85.

22. Lou Y, Guo Z, Zhu Y, Zhang G, Wang Y, Qi X, Lu L, Liu Z, Wu J. Astragali radix and its main bioactive compounds activate the Nrf2-mediated signaling pathway to induce P-glycoprotein and breast cancer resistance protein. J Ethnopharmacol. 2019;10(228):82-91.

23. Gao J, Liu ZJ, Chen T, Zhao D. Pharmaceutical properties of calycosin, the major bioactive isoflavonoid in the dry root extract of Radix astragali. Pharm Biol. 2014;52(9):1217-22.

24. Annunziata G, Jiménez-García M, Capó X, Moranta D, Arnone A, Tenore GC, Sureda A, Tejada S. Microencapsulation as a tool to counteract the typical low bioavailability of polyphenols in the management of diabetes. Food Chem Toxicol. 2020;1(139):111248-55.

25. Ahlawat J, Guillama Barroso G, Masoudi Asil S, Alvarado M, Armendariz I, Bernal J, Carabaza X, Chavez S, Cruz P, Escalante V, Estorga S. Nanocarriers as potential drug delivery candidates for overcoming the blood-brain barrier: challenges and possibilities. ACS Omega. 2020;5(22):12583-95.

26. Sahai N, Gogoi M, Ahmad N. Mathematical modeling and simulations for developing nanoparticle-based cancer drug delivery systems: a review. Curr Pathobiol Rep . 2021;6:1-8.

27. Ahmad N, Gopinath P, editors. Intelligent nanomaterials for drug delivery applications. Amsterdam: Elsevier; 2020.

28. Bai S, Zhang Y, Li D, Shi X, Lin G, Liu G. Gain an advantage from both sides: Smart size-shrinkable drug delivery nanosystems for high accumulation and deep penetration. Nano Today. 2021;1 (36):101038-45.

29. Vemuri S, Rhodes CT. Preparation and characterization of liposomes as therapeutic delivery systems: a review. Pharm Acta Helv. 1995;70(2):95-111.

30. Sharma D, Ali AA, Trivedi LR. An updated review on: liposomes as drug delivery system. PharmaTutor. 2018;6(2):50-62.

31. Le NT, Nguyen DT, Nguyen NH, Nguyen CK, Nguyen DH. Methoxy polyethylene glycol-cholesterol modified soy lecithin liposomes for poorly water-soluble anticancer drug delivery. J Appl Polym Sci. 2021;138(7):49858-65.

32. Matloob AH, Mourtas S, Klepetsanis P, Antimisiaris SG. Increasing the stability of curcumin in serum with liposomes or hybrid drug-incyclodextrin-in-liposome systems: a comparative study. Int J Pharm. 2014:476(1-2):108-15.

33. Mignet N, Seguin J, Romano MR, Brullé L, Touil YS, Scherman D, Bessodes M, Chabot GG. Development of a liposomal formulation of the natural flavonoid fisetin. Int J Pharm. 2012;423(1):69-76.

34. Caddeo C, Pucci L, Gabriele M, Carbone C, Fernàndez-Busquets X, Valenti D, Pons R, Vassallo A, Fadda AM, Manconi M. Stability, biocompatibility and antioxidant activity of PEG-modified liposomes containing resveratrol. Int J Pharm. 2018;538(1-2):40-7.

35. Wang Q, Liu W, Wang J, Liu H, Chen Y. Preparation and pharmacokinetic study of Daidzein Long-circulating liposomes. Nanoscale Res Lett. 2019;14(1):1-7. 
36. Wang $X H$, Cai $L L$, Zhang $X Y$, Deng $L Y$, Zheng $H$, Deng $C Y$, Wen JL, Zhao $X$, Wei YQ, Chen LJ. Improved solubility and pharmacokinetics of PEGylated liposomal honokiol and human plasma protein binding ability of honokiol. Int J Pharm. 2011;410(1-2):169-74.

37. Yan-yu X, Yun-mei S, Zhi-peng C, Qi-neng P. Preparation of silymarin proliposome: a new way to increase oral bioavailability of silymarin in beagle dogs. Int J Pharm. 2006;319(1-2):162-8.

38. Weinbach EC. A procedure for isolating stable mitochondria from rat liver and kidney. Anal Biochem. 1961;2(4):335-43.

39. Fraga CG, Leibovitz BE, Tappel AL. Lipid peroxidation measured as thiobarbituric acid-reactive substances in tissue slices: characterization and comparison with homogenates and microsomes. Free Radical Biol Med. 1988;4(3):155-61.

40. Brar SK, Verma M. Measurement of nanoparticles by light-scattering techniques. TrAC Trends Anal Chem. 2011;30(1):4-17.

41. Qi LW, Li P, Li SL, Sheng LH, Li RY, Song Y, Li HJ. Screening and identification of permeable components in a combined prescription of Danggui Buxue decoction using a liposome equilibrium dialysis system followed by HPLC and LC-MS. J Sep Sci. 2006;29(14):2211-20.

42. Sedlackova L, Korolchuk VI. Mitochondrial quality control as a key determinant of cell survival. Biochim Biophys Acta. 2019;1866(4):575-87.

43. Birben E, Sahiner UM, Sackesen C, Erzurum S, Kalayci O. Oxidative stress and antioxidant defense. World Allergy Organ J. 2012;5(1):9-19.

44. Ighodaro OM. Molecular pathways associated with oxidative stress in diabetes mellitus. Biomed Pharmacother. 2018;1(108):656-62.

45. Yanowsky-Escatell FG, Andrade-Sierra J, Pazarín-Villaseñor L, SantanaArciniega C, Torres-Vázquez ED, Chávez-lñiguez JS, Zambrano-Velarde MÁ, Preciado-Figueroa FM. The role of dietary antioxidants on oxidative stress in diabetic nephropathy. Iran J Kidney Dis. 2020;14(2):1-8.
46. Nasri H. Antioxidant therapy to ameliorate chronic kidney disease induced by oxidative stress; an updated mini-review. J Prevent Epidemiol. 2017:2(1):e04-09.

47. Khursheed R, Singh SK, Wadhwa S, Gulati M, Kapoor B, Awasthi A, Kr A, Kumar $\mathrm{R}$, Pottoo FH, Kumar V, Dureja H. Opening eyes to therapeutic perspectives of bioactive polyphenols and their nanoformulations against diabetic neuropathy and related complications. Expert Opin Drug Deliv. 2020;28:1-22.

48. Li Y, Zhang J, Gu J, Chen S. Biosynthesis of polyphenol-stabilised nanoparticles and assessment of anti-diabetic activity. J Photochem Photobiol, B. 2017;1 (169):96-100

49. Chen L, Gnanaraj C, Arulselvan P, El-Seedi H, Teng H. A review on advanced microencapsulation technology to enhance bioavailability of phenolic compounds: based on its activity in the treatment of type 2 diabetes. Trends Food Sci Technol. 2019;1 (85):149-62.

50. Yang S, Han Y, Liu J, Song P, Xu X, Zhao L, Hu C, Xiao L, Liu F, Zhang H, Sun L. Mitochondria: a novel therapeutic target in diabetic nephropathy. Curr Med Chem. 2017;24(29):3185-202.

51. Lindblom R, Higgins G, Coughlan M, de Haan JB. Targeting mitochondria and reactive oxygen species-driven pathogenesis in diabetic nephropathy. RDS. 2015:12(1-2):134-9.

52. Wen R, Banik B, Pathak RK, Kumar A, Kolishetti N, Dhar S. Nanotechnology inspired tools for mitochondrial dysfunction related diseases. Adv Drug Deliv Rev. 2016;1(99):52-69.

\section{Publisher's Note}

Springer Nature remains neutral with regard to jurisdictional claims in published maps and institutional affiliations.
Ready to submit your research? Choose BMC and benefit from:

- fast, convenient online submission

- thorough peer review by experienced researchers in your field

- rapid publication on acceptance

- support for research data, including large and complex data types

- gold Open Access which fosters wider collaboration and increased citations

- maximum visibility for your research: over $100 \mathrm{M}$ website views per year

At BMC, research is always in progress.

Learn more biomedcentral.com/submissions 